Article

\title{
Experimental Study on the Strengthen Heat Transfer Performance of PCM by Active Stirring
}

\author{
Yanjun Zhang ${ }^{1}{ }^{1}$, Shuli Liu ${ }^{1,2, *}$, Liu Yang ${ }^{1}$, Xiue Yang ${ }^{1}$, Yongliang Shen ${ }^{1}$ and Xiaojing Han ${ }^{1}$ \\ 1 School of Mechanical Engineering, Beijing Institute of Technology, Beijing 100081, China; \\ simpson1996@live.cn (Y.Z.); yangliu0620@126.com (L.Y.); yangxiue0607@126.com (X.Y.); \\ sheny10104@163.com (Y.S.); 3120170257@bit.edu.cn (X.H.) \\ 2 School of Energy, Construction and Environment, Coventry University, Coventry CV1 2HF, UK \\ * Correspondence: shuli.liu@coventry.ac.uk; Tel.: +44-(0)2477-657-822
}

Received: 16 March 2020; Accepted: 24 April 2020; Published: 3 May 2020

\begin{abstract}
Latent heat storage has higher energy density, but most phase change materials (PCMs) have low thermal conductivity. Current research focuses on conduction dominated heat transfer mechanism to increase the heat transfer performance. However, convection also has important effects on promoting PCM melting and solidification processes. Therefore, an active stirring method with conduction dominated heat transfer mechanism was studied. A shell storage with stirrer inside was constructed and tested. Paraffin was selected as the PCM; the heat transfer fluid (HTF) was water. The results show that average charging rate increased by $32.23 \mathrm{~J} / \mathrm{s}$ than that without stirring, and the average discharging rate increased by $47.39 \mathrm{~J} / \mathrm{s}$. Completion time for charging/discharging with stirring was shortened by $9.61 \%$ and $48.61 \%$ than that without stirring. In the charging process, the average power of motor was $16.08 \mathrm{~W}$, and the average discharging rate was greater than $500 \mathrm{~J} / \mathrm{s}$, accounting for less than $3.2 \%$. In the discharging process, the average power consumption of the motor accounted for less than $5.2 \%$ of the discharging rate. It may be considered that convection dominated heat transfer mechanism can effectively improve phase-change heat transfer performance with lower active power consumption
\end{abstract}

Keywords: phase change; convection; stirring; heat transfer; latent heat

\section{Introduction}

At present, traditional fossil energy sources such as coal, oil and natural gas account for more than $80 \%$ of total global energy consumption [1]. Traditional fossil energy sources have also brought environmental pollution and ecological damage while promoting economic growth. We are facing the dual challenge of providing sufficient energy for sustainable economic growth and reducing carbon emissions [2]. The main measures taken by countries around the world are to adjust the energy structure and transition to a low-carbon energy consumption [3], which specifically includes improving the utilization efficiency of traditional fossil energy and developing clean renewable energy [4]. The thermal energy storage technology can store the waste heat of traditional fossil energy with different utilization levels to improve the utilization efficiency. The thermal energy storage technology can also effectively solve the problem of the mismatch between the supply and demand of some renewable energy such as solar energy. Therefore, solar energy equipment can continue to operate stably. Thermal energy storage is one of the key technologies for the development of renewable energy [5].

The current thermal energy storage technologies mainly include sensible heat storage, latent heat storage and chemical heat storage [5]. Latent heat energy density is not as high as chemical heat storage density, but it is at least an order of magnitude higher than sensible heat storage. Phase change material (PCM) absorbs or releases a large amount of heat during the phase change process. The specific heat of 
water is $4.3 \mathrm{~kJ} / \mathrm{kg}$, and the latent heat of common low temperature organic PCM such as paraffin is about $180 \mathrm{~kJ} / \mathrm{kg}$ and above, which is more than 45 times that of water [6]. The latent heat of inorganic materials such as $\mathrm{LiOH}$ can reach $879 \mathrm{~kJ} / \mathrm{kg}$, and PCM also have sensible heat [7]. The melting point of PCM is relatively constant, so it is easy to meet user requirements. The segmented arrangement of PCM with different melting points is conducive to the cascade utilization of thermal energy [8]. However, the thermal conductivity of most PCMs is low. For example, the thermal conductivity of paraffin is about $0.15 \mathrm{~W} / \mathrm{m} \mathrm{K}$. This resulted in a slow charging/discharging rate of the latent heat storage system. Heat transfer performance has become an important topic in the research of latent heat storage technologies [7-9].

The methods for improving the phase change heat transfer process can be divided into two types, active and passive, according to whether the PCM is moved by an external force. During the passive heat transfer process, PCM remains static and there is no external force input. PCM and heat transfer fluid (HTF) mainly transfer heat through conduction heat transfer mechanism. The theory of enhancing heat transfer performance by conduction mainly includes increasing the heat transfer area and increasing the thermal conductivity of the PCM module. Specific methods to increase the heat transfer area are adding fins [10], heat pipes [11] or encapsulated PCM [12,13]. Specific methods to increase the thermal conductivity of the PCM module include adding highly thermally conductive substances to the PCM [14,15], incorporated into expanded graphite or foam metal interiors [16,17]. The method of enhancing heat transfer performance by conduction is effective, especially in the solidification process of PCM, because the solidification process is dominated by the conduction mechanism [18]. However, after the PCM solidified on the heat transfer surface and gradually thickened, it will increase the heat transfer resistance between the liquid PCM and heat transfer surface, and reducing the thickness of the solid PCM on the heat transfer surface can increase the heat transfer rate. Zipf [19] designed a double-helix structure to strengthen the heat transfer of PCM during solidification process. The self-cleaning function of the double-helix shaft can make the solid PCM off the heat transfer surface. When the mass flow rate of the liquid PCM is $50 \mathrm{~L} / \mathrm{h}, 11 \mathrm{~kW}$ of thermal energy can be obtained. However, the double spiral structure in the charging process was not ideal because the solid PCM is difficult to closely adhere to the surface of the spiral shaft, which reduces effective heat transfer area. The double-helix structure is actually a heat transfer model that is dominated by convection. Zipf's research shows that it is feasible to enhance the heater transfer performance by convection dominated heat transfer during PCM solidification process. In the process of PCM melting, convection is the dominant heat transfer mechanism [20,21]. Xia Li [22] studied the natural convection, solidification sinking and volume expansion of the PCM melting process. Through numerical methods, it was found that the liquid fraction of paraffin calculated only by the thermal conductivity model after melting for $130 \mathrm{~min}$ was $13.4 \%$. However, the liquid fraction calculated by the model considering natural convection for $130 \mathrm{~min}$ has reached above $97 \%$. During the peak period of natural convection, the maximum melting rate of paraffin was $0.2005 \%$ per second, which was much higher than the average melting rate of $0.125 \%$ per second. Xia Li's research shows that natural convection plays an important role in promoting PCM melting rate. In order to improve the heat transfer performance of PCM, according to Zipf [19] and Xia Li's [22] research, it is feasible to enhance convection heat transfer both in PCM melting and solidification processes.

Based on the above studies, in order to enhance the heat transfer performance of the latent heat storage, an active stirring heat transfer model is proposed, and the effect of convection on the phase change heat transfer process is studied. This model mainly uses stirrer to stir the PCM, thereby enhancing the convective heat transfer between the PCM and heat transfer surface. First is to set up an experimental test model to verify the principle. Then to determine the main factors that affect the heat transfer rate, including the stirring speed, HTF inlet temperature, HTF mass flow. Finally, exploring the relationship between active stirring energy consumption and heat transfer rate during charging/discharging processes. 


\section{Materials and Methods}

\subsection{Materials Selection}

\subsubsection{Phase Change Material}

Solid-liquid phase change materials can be broadly divided into organic, inorganic and composite phase change materials [7]. Organic materials are mainly paraffin and non-paraffin fatty acids and alcohols, which have the advantage of stable chemical properties, but low thermal conductivity.

In order to test the active stirring heat transfer model, paraffin with a melting temperature of $58.13^{\circ} \mathrm{C}$ was selected, which has the advantages of large latent heat, low volatility, non-toxicity, good stability and no overcooling. The experimental paraffin had a purity of more than $98 \%$. As presented in Figure 1, DSC was used to measure the paraffin phase change temperature. The latent heat of phase change process was $188.26 \mathrm{~kJ} / \mathrm{kg}$, the solid sensible heat $C_{p, s}$ was $1.72 \mathrm{~kJ} / \mathrm{kg} \mathrm{K}$, and the liquid sensible heat $C_{p, l}$ was $0.72 \mathrm{~kJ} / \mathrm{kg} \mathrm{K}$.

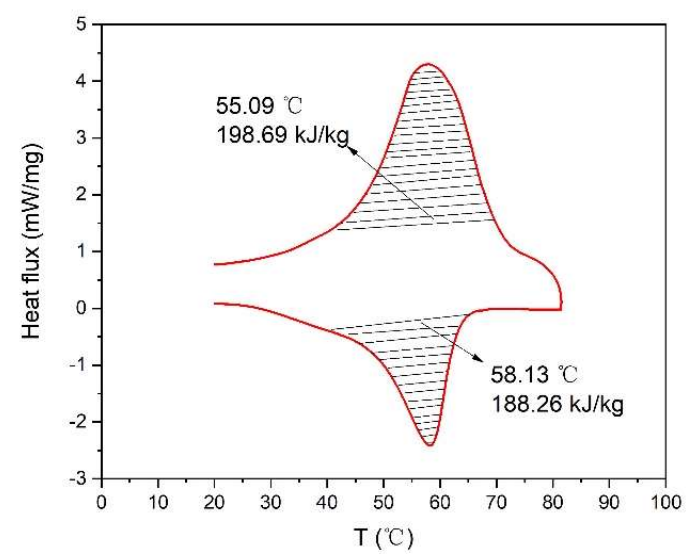

Figure 1. Phase change temperature and specific heat capacity of paraffin wax with differential scanning calorimetry (DSC).

\subsubsection{Shell Container for PCM}

Generally, there is no direct contact between PCM and HTF for heat transfer, because this will lead to problems such as blending loss and how to separate it [23]. Basic structures of the heat exchangers are presented in Figure 2. There are plate type, shell and tube type and packed bed type. In these structures, the PCM always remains static without motion, and the dominant heat transfer mechanism of PCM is conduction.

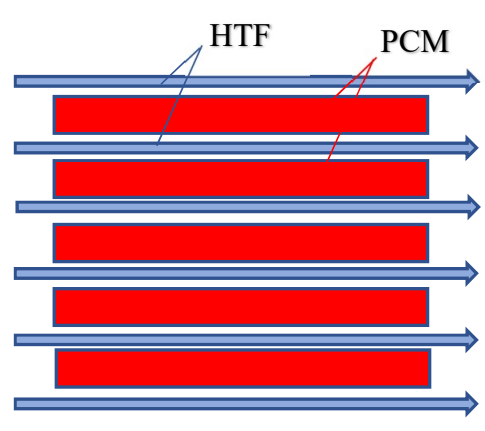

(a)

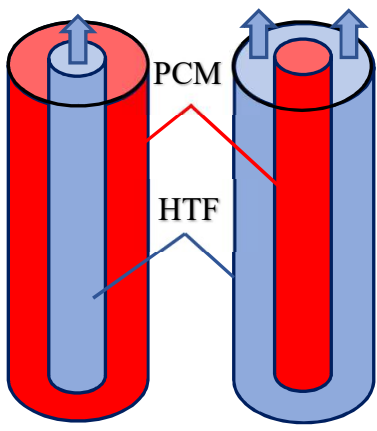

(b)

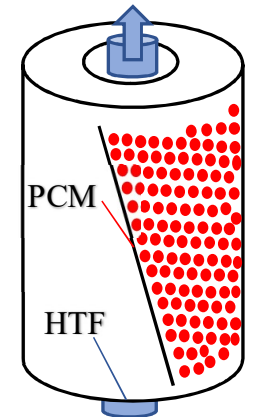

(c)

Figure 2. Common phase change heat exchange structures [23]. (a) Plate type, (b) shell and tube type, (c) packed-bed type. 
PCM should move to form convection. Shell and tube type suitable for installing the stirrer. The structure of outer column was selected for HTF for three reasons: First, the PCM is all solid at the initial process of melting and has a large friction with the heat transfer surface. Once the outer layer PCM absorbs heat and softens, the stirring resistance moment will be significantly reduced, so stirring can be quickly start. Second, during the PCM solidification process, the outermost layer of PCM of the inner column starts to solidify first. Stirring and scraping off the solidified PCM can reduce the thermal resistance. Finally, if the outer column is PCM, the PCM outside the outer column is difficult to stir during the initial charging process due to the large friction between the solid PCM and the surface of the package. Based on the above three points, the design of the inner column PCM and the outer column HTF is determined. In order to reduce heat loss, on the outside of the outer column wrapped $2.5 \mathrm{~cm}$ thick thermal insulation material.

\subsubsection{Stirrer}

The existing stirring equipment is mainly used in petrochemical, pharmaceutical and other industries [24], the purpose of which is to promote more comprehensive chemical reaction and enhance heat and mass transfer. Stirring is also used in the field of food processing for scraper type heat exchanger [25]. The selection of stirrers is generally considered from three aspects: the purpose of stirring, the viscosity of the material and the volume of the stirring container. In addition, factors such as low power consumption, low operating costs and ease of manufacturing, maintenance should be considered. Typical stirrer types are paddle, turbine, anchor, frame and ribbon, etc. [26,27]. The structures are presented in Figure 3.

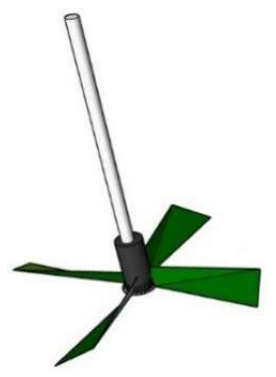

(a)

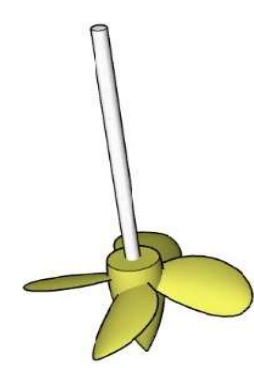

(b)

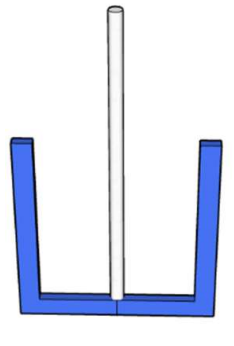

(c)

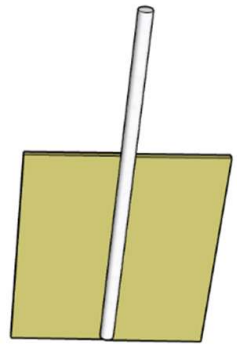

(d)

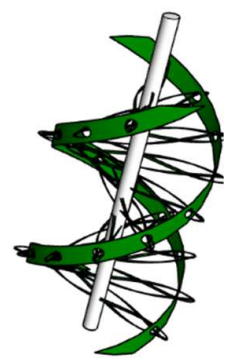

(e)

Figure 3. Different stirrer types. (a) Paddle type, (b) turbine type; (c) anchor type, (d) frame type, (e) ribbon type.

The paddle type stirrer (a) mainly stirs high-viscosity liquids of about 50 Pa with a stirring speed of 20-100 $\mathrm{r} / \mathrm{min}$. The turbine-type stirrer (b) is the similar to the paddle stirrer. It mainly stirs liquid with a viscosity of about $30 \mathrm{~Pa}$ and stirring speed is 50-300 r/min. In the anchor type stirrer (c), the diameter of the blade of the anchor stirrer is closer to the diameter of the tank, and it usually runs at a low rotation speed generally $10-50 \mathrm{r} / \mathrm{min}$. The anchor stirrer has large shearing force. It is suitable for stirring high viscosity liquids 200-300 Pa. The frame type stirrer (d) is similar to the anchor stirrer. The stirring speed is generally $60-130 \mathrm{r} / \mathrm{min}$. The ribbon type stirrer (e) has spiral-shaped stirring blades, which are mainly used to stir high-viscosity liquids or wet mud-like liquids.

The active stirring heat transfer model requires the PCM to be forced move to form convective heat transfer. There are three reasons for choosing the anchor type stirrer as the proper stirrer. First, liquid paraffin will gradually solidify during the discharging process, and the solid PCM has a large frictional force with the blade. The blade should try to overcome the frictional torque and keep stirring for a long time so that the PCM can fully perform forced convective heat transfer. The anchor type stirrer has the largest stirring torque. Second, a large speed is not required during the solidification process of PCM, as it takes some time for the liquid PCM to release heat on the heat transfer surface. The anchor type stirrer has a stirring speed of $10-50 \mathrm{r} / \mathrm{min}$. Finally, in order to reduce the thermal 
resistance of the solid PCM heat transfer surface of the inner column, stirring should mainly focus on the heat transfer surface rather than center of the inner column. The anchor type stirrer mainly stirs the substance near the tank wall. Based on the above three points, the anchor stirrer was selected.

\subsection{Experimental Test Rig}

An experimental test rig was set up based on the principle of enhanced phase change heat transfer performance by active stirring. Thermocouples measured the temperature to verify the principle and determine the rate of charging/discharging. Test rig can also determine the effects of HTF mass flow, HTF inlet temperature and stirring speed on the heat transfer rate.

The system parameters are shown in Table 1. Both inner and outer columns and the stirring shaft are made of 304 stainless steel, which is corrosion resistant and has a high thermal conductivity. In order to avoid the long-term scraping of the stirrer on the heat transfer surface, surface of stirrer used tetrachloride to protect.

Table 1. Structural parameters of active stirring phase change test rig.

\begin{tabular}{cccc}
\hline Description & Value & Description & Value \\
\hline Inner column height & $400 \mathrm{~mm}$ & Inner column diameter & $110 \mathrm{~mm}$ \\
Inner tube wall thickness & $2 \mathrm{~mm}$ & Outer column diameter & $128 \mathrm{~mm}$ \\
Stirring shaft height & $390 \mathrm{~mm}$ & Stirring shaft diameter & $8 \mathrm{~mm}$ \\
Mass of columns & $15.1 \mathrm{~kg}$ & 304 stainless steel specific heat capacity & $0.5 \mathrm{~kJ} / \mathrm{kg} \mathrm{K}$ \\
Paraffin mass & $2.7 \mathrm{~kg}$ & Stirring speed range & $0-60 \mathrm{r} / \mathrm{min}$ \\
\hline
\end{tabular}

The real application of the active stirring model is presented in Figure 4a. The experimental test rig is presented in Figure $4 \mathrm{~b}$. The test rig mainly included five parts: shell container to store paraffin, stirring speed control, HTF inlet temperature control, HTF mass flow control and experimental data collection. HTF is the water. During the charging process, the water tank No. 1 used an electric heater to keep the HTF inlet temperature at a constant value. HTF entered from the bottom of the shell container and flowed out from the top of the shell container. Then HTF flowed to the tank No. 2 . Solid paraffin in contact with the heat transfer surface heated and softened, and then was stirred. K-type thermocouples were used to measure the temperature of the HTF and determine the thermal parameters of the heat transfer process. From the bottom to the top of the outer column of shell container, there were 7 thermocouples arranged at intervals of $50 \mathrm{~mm}$. Thermocouples were adjusted before use, and the measurement accuracy was $\pm 0.5^{\circ} \mathrm{C}$. HTF mass flow was measured by a meter with a range of $0.5-15 \mathrm{~L} / \mathrm{min}$. A data collector model MR71VO1K15X was used to collect the data of mass flow rate, temperature and pressure. Stirring speed of the motor was $1250 \mathrm{r} / \mathrm{min}$ with rated power $90 \mathrm{~W}$, and a 25:1 gear reducer was used to increase the torque. The output speed of the motor was adjusted through frequency conversion. The stirring speed adjustment range was 0-60 r/min. Active stirring energy consumption was measured by power meter which was connected in series to the electric motor. 


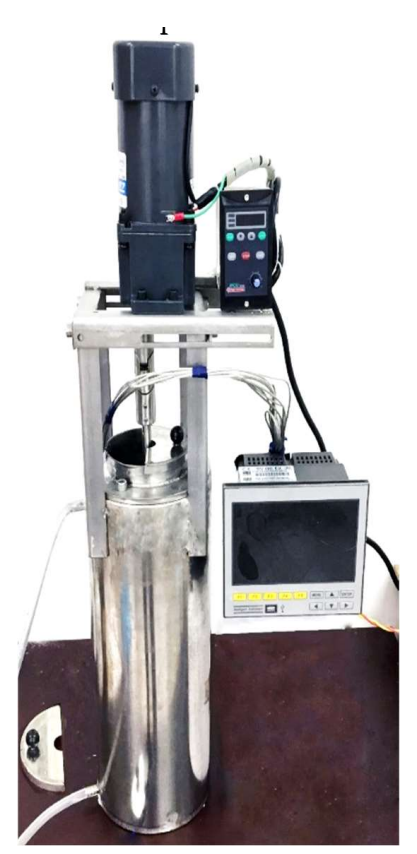

(a)

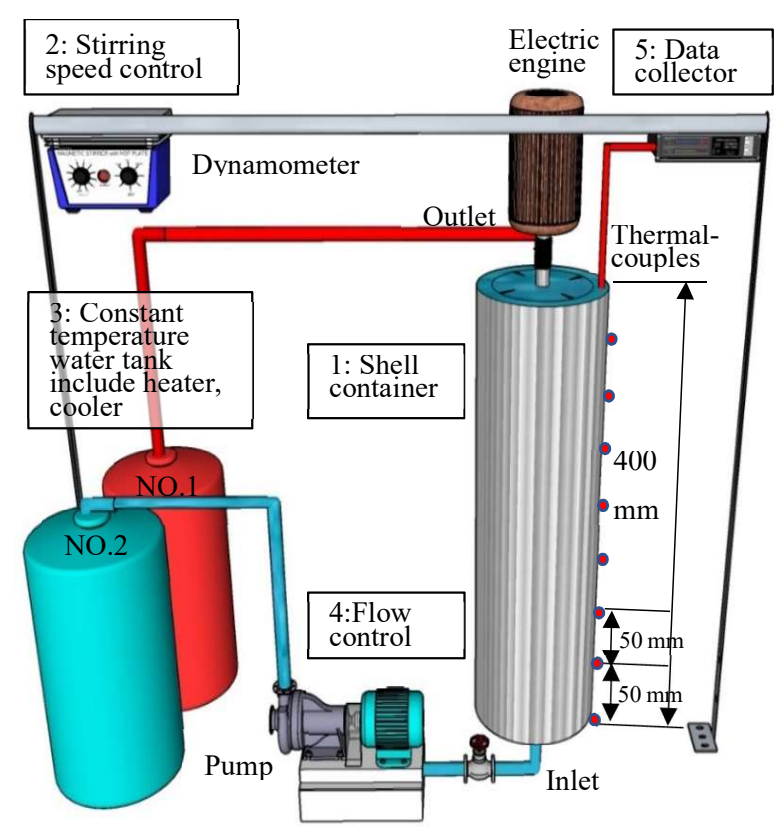

(b)

Figure 4. (a) Real application of active stirring phase change heat transfer model, (b) experiment test rig.

\subsection{Experiment Data}

The determination of the total heat transferred time has an important impact on the analysis of the average heat transfer rate and the comparison of heat transfer effects with and without stirring. It is important to determine the phase change period time during the charging/discharging processes. However, it is difficult to determine it directly, hence an indirectly method was applied. According to the experiment and as presented in Figure 5a, the inlet temperature of HTF was higher than the outlet temperature of HTF due to the heat transferred to the PCM during the charging process. The inlet and outlet temperature difference of HTF at $2549 \mathrm{~s}$ and $4058 \mathrm{~s}$ was the same, which indicated that from $2549 \mathrm{~s}$ there no more heat transferred from HTF to PCM. From $2549 \mathrm{~s}$, transferred heat was all lost. In Figure 5a, $2549 \mathrm{~s}$ was the total charging time. During the discharge process, as presented in Figure $5 b, 2480 \mathrm{~s}$ was the total discharging time. The total amount of transferred heat was determined according to the total charging/discharging time.

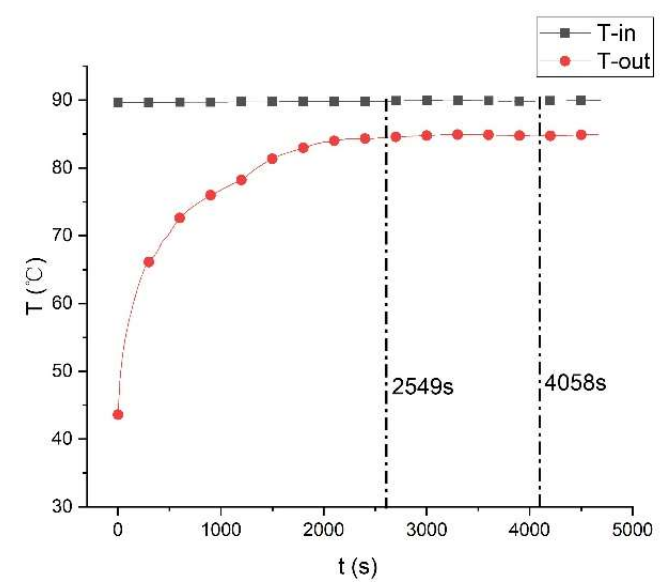

(a)

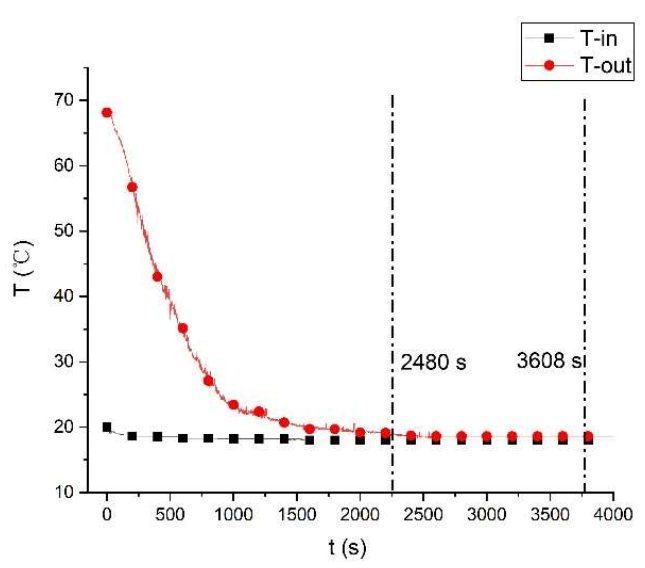

(b)

Figure 5. (a) Inlet and outlet temperatures of HTF during charging process, (b) inlet and outlet temperatures of HTF during discharging process. 
In order to determine the heat storage capacity, average charging/discharging heat rates, charging/discharging efficiencies and overall thermal efficiency, the following equations were used:

Theoretical heat storage is shown in Equation (1):

$$
Q_{\text {stored }}=m_{p c m}\left(h_{p c, f i n}-h_{p c, \text { ini }}\right)+\int_{T_{\text {ini }}}^{T_{\text {fin }}} m_{\text {shell }} C_{p, \text { shell }} d T+\int_{T_{\text {ini }}}^{T_{\text {fin }}} m_{\text {shaft }} C_{p, \text { shaft }} d T
$$

During the charging process, the heat transferred from HTF to PCM is Equation (2):

$$
Q_{\text {charge }}=\int_{0}^{\tau} m_{f} C_{p, f}\left(T_{f, \text { in }}-T_{f, \text { out }}\right) d t
$$

During the discharging process, the heat transferred from PCM to HTF is Equation (3):

$$
Q_{\text {discharge }}=\int_{0}^{\tau} m_{f} C_{p, f}\left(T_{f, o u t}-T_{f, \text { in }}\right) d t
$$

The average charging rate is Equation (4):

$$
q_{\text {ave, charge }}=\frac{Q_{\text {charge }}}{\tau_{\text {charge }}}
$$

The average discharging rate is Equation (5):

$$
q_{\text {ave,discharge }}=\frac{Q_{\text {discharge }}}{\tau_{\text {discharge }}}
$$

The charging efficiency is Equation (6):

$$
\eta_{\text {charge }}=\frac{Q_{\text {stored }}}{Q_{\text {charge }}}
$$

The discharge efficiency is Equation (7):

$$
\eta_{\text {discharge }}=\frac{Q_{\text {discharge }}}{Q_{\text {stored }}}
$$

$h_{p c, i n i}$ and $h_{p c, \text { fin }}$ represent the enthalpy values of the PCM at initial and final temperatures, which obtained from DSC. $C_{p \text {,shell }}$ and $C_{p \text {,shaft }}$ represent the specific heat capacity of the shell container and the stirring shaft, respectively. $T_{f, \text { in }}$ and $T_{f, \text { out }}$ represent the temperatures of HTF at the inlet and outlet of the shell container, respectively. $\mathrm{m}_{\mathrm{f}}$ represents the mass flow of the HTF. $\tau_{\text {charge }}$ and $\tau_{\text {discharge }}$ represent the duration of the charging/discharging processes. $Q_{\text {stored }}$ is the theoretical heat storage capacity, including paraffin latent heat and sensible heat of paraffin, shaft and shell. The overall thermal efficiency during the charging/discharging processes is the ratio of the discharging heat to the charging heat. The expression is Equation (8). $Q_{\text {charge }}$ and $Q_{\text {discharge }}$ represent the charged heat transferred from HTF to PCM and the discharged heat transferred from PCM to HTF, respectively.

$$
\eta_{\text {overall }}=\frac{Q_{\text {discharge }}}{Q_{\text {charge }}}=\eta_{\text {charge }} \times \eta_{\text {discharge }}
$$

\subsection{Experiment Error Analysis}

Due to the inaccuracy of the experiment equipment and calculation method, experimental errors were inevitable. In order to analyze the credibility of the experiment results, an error analysis was performed. First, analyzing the error of the experiment instrument. Due to the inaccuracy of the 
mass flow meter, according to the experiment results, the maximum relative error $\mathrm{u}_{1}$ of the HTF mass flow was less than $4 \%$. Due to temperature fluctuation in the constant temperature water tank, the maximum relative error $\mathrm{u}_{2}$ of the HTF inlet temperature was less than $2 \%$. Thermocouple measurement accuracy was $\pm 0.5{ }^{\circ} \mathrm{C}$, and the maximum relative error $\mathrm{u}_{3}$ was less than $2.5 \%$. Second, the error of the calculation method was analyzed. HTF in the theoretical formula used the same specific heat capacity at constant pressure, however, water has different specific heat at different temperatures in practice, so the calculation error $\mathrm{u}_{4}$ was less than $0.5 \%$. According to the uncorrelated error transmission Formula (9):

$$
u_{c}=\sqrt{\mathrm{u}_{1}^{2}+u_{2}^{2}+u_{3}^{2}+\cdots u_{n}^{2}}
$$

The relative error of the experiment's charging/discharging heat, charging/discharging rates and charging/discharging efficiencies were less than $4.1 \%$ and the relative error of the overall thermal efficiency was less than $5.7 \%$.

\section{Results and Discussion}

\subsection{Principle Verification of Convection}

Moving the PCM by stirring to form convective is the principle of heat transfer enchantment of active stirring phase change model. First, the temperature difference should be nearly $30^{\circ} \mathrm{C}$ between PCM and HTF for a good heat transfer rate. The PCM melting temperature is $58.13^{\circ} \mathrm{C}$, so the HTF inlet temperature during charging process was selected $90^{\circ} \mathrm{C}$, the HTF inlet temperature during discharging process was selected $20^{\circ} \mathrm{C}$. Assuming the average heat transfer coefficient is $200 \mathrm{~W} / \mathrm{m}^{2} \mathrm{~K}$ [28], according to heat transfer balance and the HTF pump capacity, the mass flow rate of HTF was selected $42 \mathrm{~L} / \mathrm{h}$. In order to compare and analyze the effect of convection on the phase change heat transfer process, the experiment was divided into two cases: stirring and non-stirring. The stirring rate was $40 \mathrm{r} / \mathrm{min}$ during charging process and $20 \mathrm{r} / \mathrm{min}$ during discharging process. According to the experimental process, the HTF quickly heated the inner column wall during the initial process of charging and the paraffin that close to the heat transfer surface absorbed heat and began to soften. From the start of the HTF flowing out from outer column, after about $10 \mathrm{~s}$ the stirring shaft overcame the frictional resistance between the paraffin and the inner column wall and started working towards the end of the charging process. During the discharging process, the frictional resistance between the PCM and the inner column wall increased due to the gradual solidification of the liquid PCM, which caused the anchor stirrer to stop stirring near $840 \mathrm{~s}$.

As presented in Figure 6a, it can be observed that from the beginning of the discharging process to the $866 \mathrm{~s}$, the average discharging rate of the stirring was always greater than without the stirring, more than $264.97 \mathrm{~J} / \mathrm{s}$. As presented in Figure $6 \mathrm{~b}$, the average charging rate with stirring was also greater than without stirring, more than $58.12 \mathrm{~J} / \mathrm{s}$. Although from the $382 \mathrm{~s}$ to $973 \mathrm{~s}$, the process without stirring had a higher heat transfer rate than stirring. As presented in Table 2, the charging/discharging completion time with stirring had been shortened by $9.61 \%$ and $48.61 \%$ compared to without stirring, respectively. According to the increased heat transfer rate and reduced charging/discharging completion time, the active stirring model had successfully improved the heat transfer performance of phase change process. 


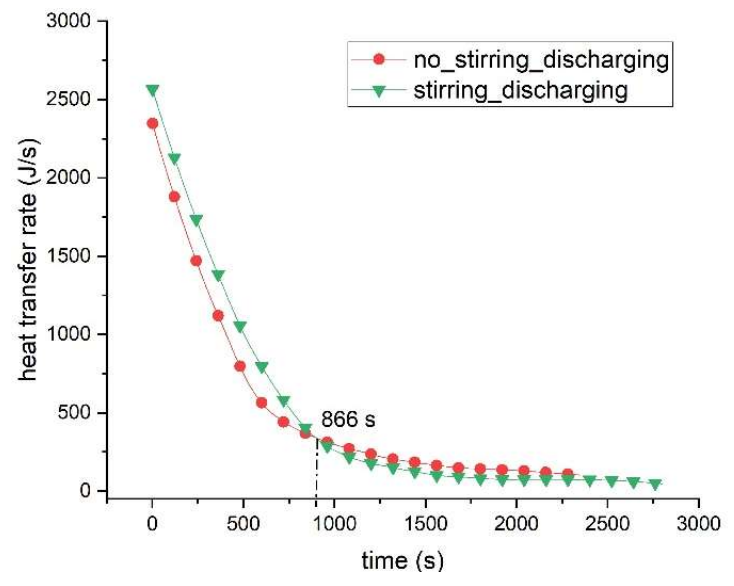

(a)

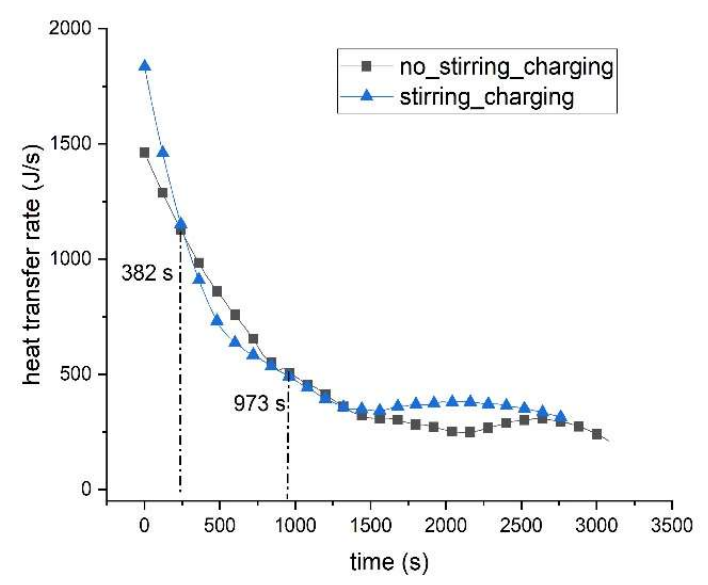

(b)

Figure 6. (a) Heat transfer rates during discharging processes with and without stirring, (b) heat transfer rates during charging processes with and without stirring.

Table 2. Comparison of stirring and non-stirring heat transfer process parameters.

\begin{tabular}{ccccc}
\hline Description & $\begin{array}{c}\text { No-Stirring } \\
\text { Charging }\end{array}$ & $\begin{array}{c}\text { No-Stirring } \\
\text { Discharging }\end{array}$ & $\begin{array}{c}\text { Stirring } \\
\text { Charging }\end{array}$ & $\begin{array}{c}\text { Stirring } \\
\text { Discharging }\end{array}$ \\
\hline Efficiency $(\%)$ & 89.62 & 88.14 & 88.67 & 87.89 \\
Average heat transfer rate (J/s) & 491.93 & 510.08 & 550.05 & 989.88 \\
Completion time (s) & 3081 & 2347 & 2785 & 1206 \\
Charged/discharged heat $(\mathrm{kJ})$ & 1458.83 & 1197.16 & 1531.88 & 1193.79 \\
\hline
\end{tabular}

\subsection{Impact Factors on the Heat Transfer Rate}

\subsubsection{Mass Flow Rate}

Three mass flow rates of $50 \mathrm{~L} / \mathrm{h}, 75 \mathrm{~L} / \mathrm{h}$ and $100 \mathrm{~L} / \mathrm{h}$ were tested for the charging/discharging processes, respectively. The stirring speed of the stirrer was constant at $30 \mathrm{r} / \mathrm{min}$. The HTF inlet temperature during charging process was uniformly $90^{\circ} \mathrm{C}$, and the $\mathrm{HTF}$ inlet temperature during discharging process was uniformly $20^{\circ} \mathrm{C}$.

As presented in Figure $7 \mathrm{a}$, mass flow from $50 \mathrm{~L} / \mathrm{h}$ to $100 \mathrm{~L} / \mathrm{h}$, the charging/discharging time shortened from $3084 \mathrm{~s} / 974 \mathrm{~s}$ to $1891 \mathrm{~s} / 604 \mathrm{~s}$, decreased by $38.78 \%$ and 37.99\%, respectively. As presented in Figure $7 \mathrm{~b}$, the average charging rate had a $90.48 \%$ increase from $501.3 \mathrm{~J} / \mathrm{s}$ to $954.9 \mathrm{~J} / \mathrm{s}$ for the flow rate varying from $50 \mathrm{~L} / \mathrm{h}$ to $100 \mathrm{~L} / \mathrm{h}$. The average discharging rate had a $64.15 \%$ improvement from $1202.7 \mathrm{~J} / \mathrm{s}$ to $1974.2 \mathrm{~J} / \mathrm{s}$. It can be considered that with the increasing of HTF mass flow rate, the completion time of charging/discharging heat continuously reduced, and the heat transfer rates of charging/discharging significantly increased. The main reason is increased in the mass of the HTF per unit time made the HTF velocity increase, and the heat transfer coefficient increased.

As presented in Figure 8, thermal efficiency during charging process decreased with increasing mass flow. This is because HTF of $100 \mathrm{~L} / \mathrm{h}$ would make the shell reach a high temperature more quickly than $50 \mathrm{~L} / \mathrm{h}$, and the shell began to dissipate heat earlier. Heat loss is inevitable and charging efficiency mainly depends on heat loss. The more heat loss, the lower charging efficiency will be. Due to the same mass flow rate and same inlet temperature of HTF during the discharging process, the discharging efficiencies were almost the same. Therefore, in order to improve the overall thermal efficiency of the system, the mass flow rate should be reduced, but at the same time the heat transfer time will be increased. To balance efficiency and heat transfer rate, specific consideration should be made according to actual needs. 


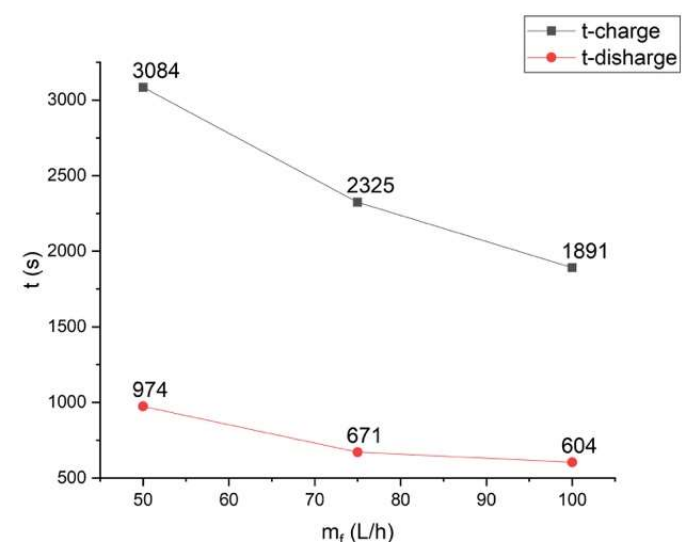

(a)

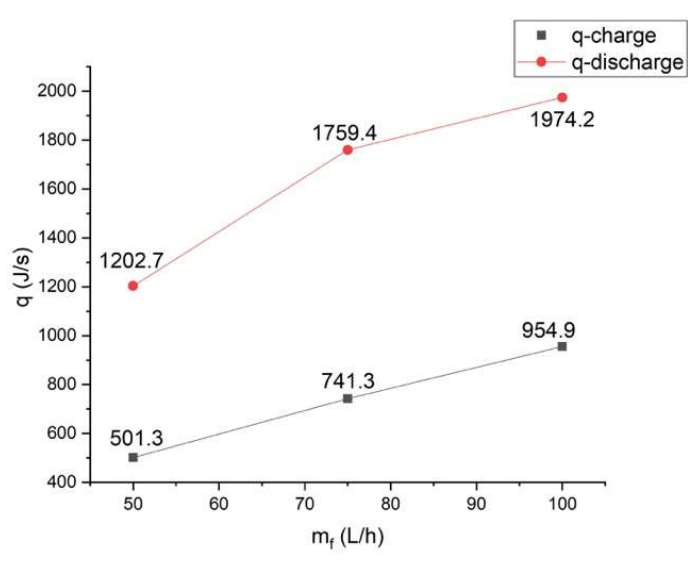

(b)

Figure 7. (a) Charging/discharging completion time under different mass flow rates, (b) charging/ discharging average heat transfer rates under different mass flow rates.

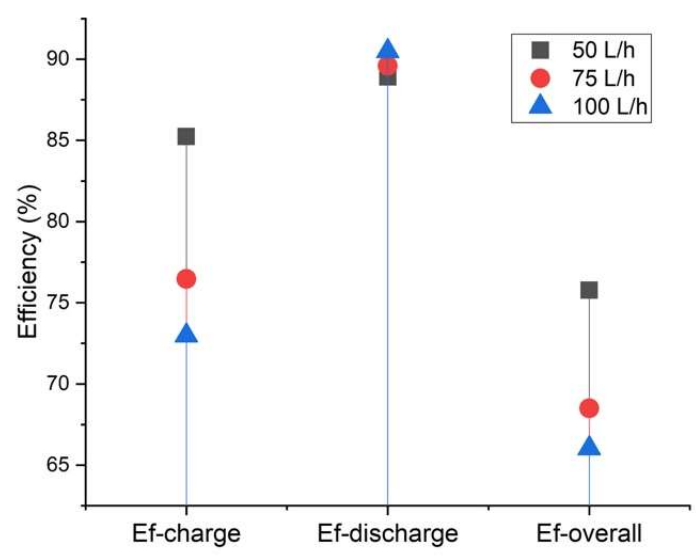

Figure 8. Charging/discharging efficiencies under different mass flow rates.

\subsubsection{Inlet Temperature of HTF}

Three different inlet temperatures of HTF were tested to analyze the effect on the heat transfer rate of charging/discharging, which were $80^{\circ} \mathrm{C}, 90^{\circ} \mathrm{C}, 100^{\circ} \mathrm{C}$. HTF mass flow was uniformly $50 \mathrm{~L} / \mathrm{h}$, and the HTF inlet temperature during the discharging process was $20^{\circ} \mathrm{C}$. The stirring speed of the stirring shaft was constant under $30 \mathrm{r} / \mathrm{min}$.

As presented in Figure 9a, with the increasing of HTF inlet temperature, the average charging rate increased rapidly. The larger temperature difference, the higher heat transfer rate will be. From $80^{\circ} \mathrm{C}$ to $100{ }^{\circ} \mathrm{C}$, the charging rates varied from $423.3 \mathrm{~J} / \mathrm{s}$ to $766.9 \mathrm{~J} / \mathrm{s}$ with an increase of $81.17 \%$. The reason is large temperature difference enhanced the heat transfer. As presented in Figure $9 \mathrm{~b}$, increasing in the charging rate would shorten the time required for charging process. The charging time for the HTF at $80^{\circ} \mathrm{C}$ and $100{ }^{\circ} \mathrm{C}$ shortened by $24.37 \%$ from 3319 s to 2510 s. As presented in Figure 10 a, as the inlet temperature of HTF increased, the charging/discharging were all increased. HTF transferred $1404.9 \mathrm{~kJ}$ heat at inlet temperature of $80^{\circ} \mathrm{C}$ and transferred $1924.9 \mathrm{~kJ}$ heat at $100{ }^{\circ} \mathrm{C} \mathrm{HTF}$. Discharging heat of $100{ }^{\circ} \mathrm{C}$ HTF was $1359.5 \mathrm{~kJ}$ which higher than $80^{\circ} \mathrm{C}$ HTF by $30.94 \%$. 


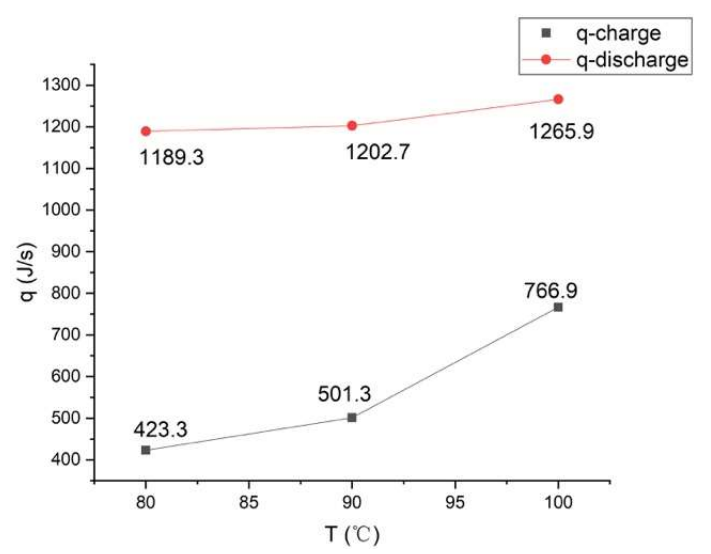

(a)

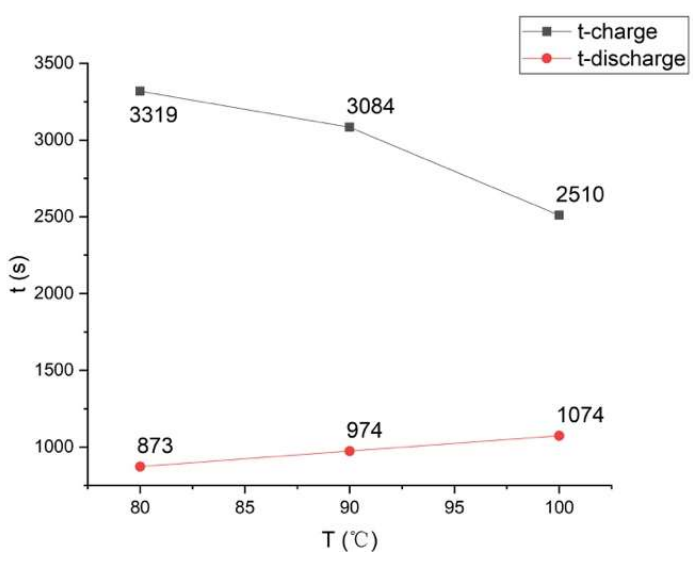

(b)

Figure 9. (a) Charging/discharging average heat transfer rates under different inlet HTF temperatures, (b) charging/discharging completion time under different inlet HTF temperatures.

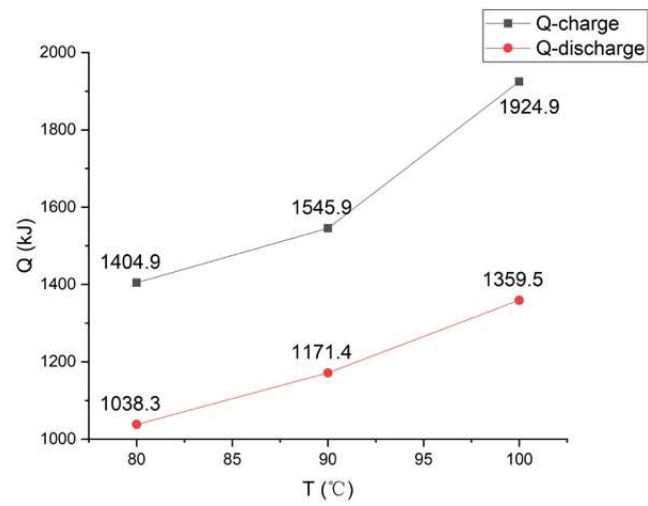

(a)

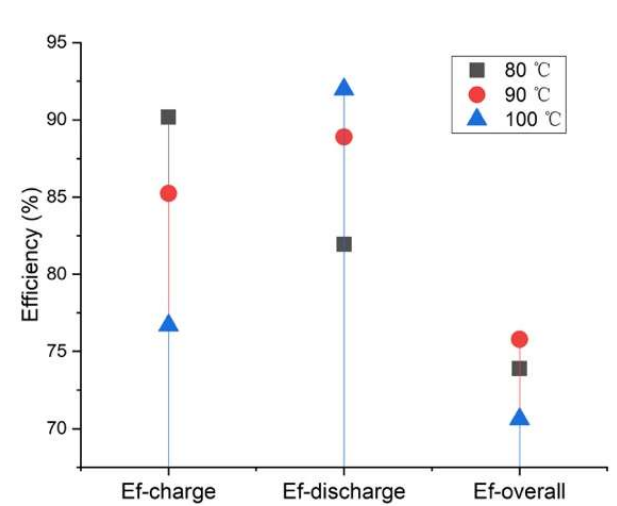

(b)

Figure 10. (a) Charging/discharging heat under different inlet HTF temperatures, (b) charging/ discharging efficiencies under different inlet HTF temperatures.

As presented in Figure 10b, first, the maximum charging efficiency under the condition of $80{ }^{\circ} \mathrm{C} \mathrm{HTF}$ was $90.18 \%$, and the minimum charging efficiency under the condition of $100{ }^{\circ} \mathrm{C} \mathrm{HTF}$ was $76.69 \%$. It can be considered that during charging process, the lower the inlet temperature, the higher the system's charging efficiency. This is because higher inlet HTF temperature resulted more heat loss during the charging process. Second, the heat discharged from $100{ }^{\circ} \mathrm{C}$ case was the highest and the efficiency was the largest. This is because during the discharging process, the case of $100{ }^{\circ} \mathrm{C}$ HTF discharged more heat than $80^{\circ} \mathrm{C}$ HTF. The charging/discharging efficiencies mainly depend on charging/discharging heat amount and heat loss. Under the same thermal insulation condition and same mass flow of HTF and inlet temperature of HTF during discharging process, the heat loss is nearly the same and discharging efficiency mainly depends on the discharging heat. Discharging more heat will result in a higher efficiency. Third, the case for the $90{ }^{\circ} \mathrm{C} \mathrm{HTF}$ had the highest overall efficiency, because the heat loss was smaller than case of $100{ }^{\circ} \mathrm{C}$ during the charging process and charging heat was larger than case of $80{ }^{\circ} \mathrm{C}$ during the discharging process. Therefore, in order to improve the thermal efficiency, it is necessary to reduce the heat loss and increase the charging/discharging heat under the same heat loss condition.

\subsubsection{Stirring Speed}

Three different stirring speeds of $10 \mathrm{r} / \mathrm{min}, 30 \mathrm{r} / \mathrm{min}$ and $50 \mathrm{r} / \mathrm{min}$ were tested to analyze the influence of the stirring speed on the charging/discharging rate. The HTF inlet temperature during 
charging process was $90^{\circ} \mathrm{C}$, and the $\mathrm{HTF}$ inlet temperature during discharging process was $20^{\circ} \mathrm{C}$. Mass flow was $50 \mathrm{~L} / \mathrm{h}$.

First, the stirring had a more significant effect on the discharging process than the charging process. As presented in Figure 11a, both the average heat transfer rate during the charging and discharging processes increased with the stirring speed. However, charging rate increased by $13.59 \%$ from $480.6 \mathrm{~J} / \mathrm{s}$ to $545.9 \mathrm{~J} / \mathrm{s}$, and discharging rate increased by $33.49 \%$ from $1046.9 \mathrm{~J} / \mathrm{s}$ to $1397.5 \mathrm{~J} / \mathrm{s}$, which was more than double growth rate of the charging process.

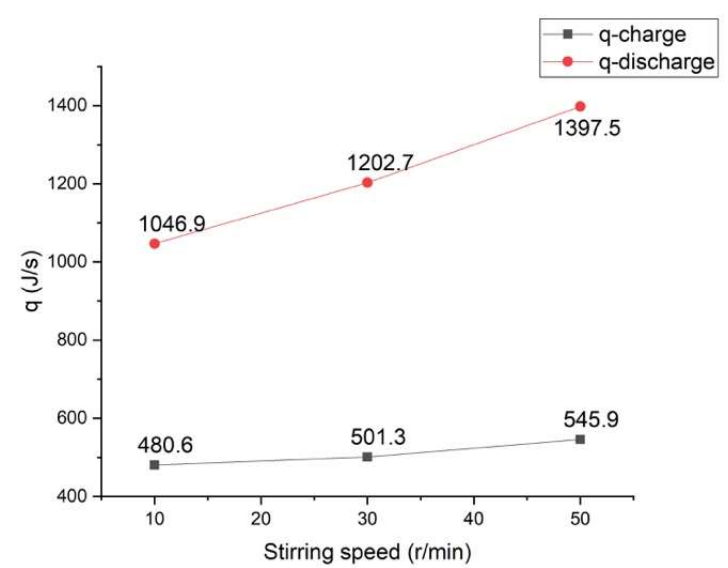

(a)

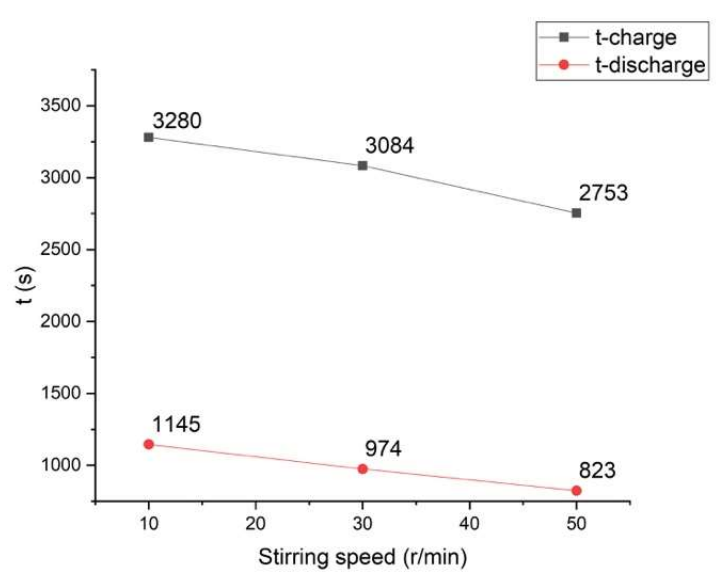

(b)

Figure 11. (a) Charging/discharging rate under different stirring speeds, (b) charging/discharging completion time under different stirring speeds.

Second, increasing in stirring speed significantly reduced the heat transfer time. As presented in Figure 11b, from $10 \mathrm{r} / \mathrm{min}$ to $50 \mathrm{r} / \mathrm{min}$, the charging time declined by $16.07 \%$ and the discharging time declined by $28.13 \%$. As the stirring speed increased, the movement speed of liquid paraffin during charging process increased inducing both the Reynolds number and the heat transfer coefficient increased. During the discharging process, increasing the stirring speed accelerated the solid paraffin leaving the heat transfer surface of the inner column wall, enlarging the probability of the liquid paraffin approaching to the heat transfer surface, and then the discharging time shortened.

Finally, as presented in Figure 12, the charging efficiency increased with the increasing of stirring speed. Charging efficiency of $50 \mathrm{r} / \mathrm{min}$ stirring speed was more $4 \%$ than $10 \mathrm{r} / \mathrm{min}$ stirring speed. Increasing in the stirring speed fastened the liquid paraffin velocity, and then inducing the heat transfer coefficient increased, which reduced the heat transfer time and the heat loss was less. Charging efficiency increased with heat loss decreasing. In the discharging process, efficiency decreased with speed increasing. Discharging efficiency of $10 \mathrm{r} / \mathrm{min}$ stirring speed was more $3 \%$ than $50 \mathrm{r} / \mathrm{min}$ stirring speed. This is because the average discharging rate in $50 \mathrm{r} / \mathrm{min}$ stirring speed was larger than $10 \mathrm{r} / \mathrm{min}$ stirring speed under same inlet temperature and mass flow rate of HTF. High discharging rate from PCM to the HTF also made more heat transferred from HTF to the shell, which led to the more heat loss. Heat loss during later part of discharging process was not sensitive to the efficiency, because temperature of HTF was lower than initial stage of discharging. Comprehensive heat transfer efficiency was basically the same at the three speeds. In order to improve the efficiency, stirring speed should increase during charging process and should decrease during discharging process, but the effect on the heat transfer rate must also be considered. 


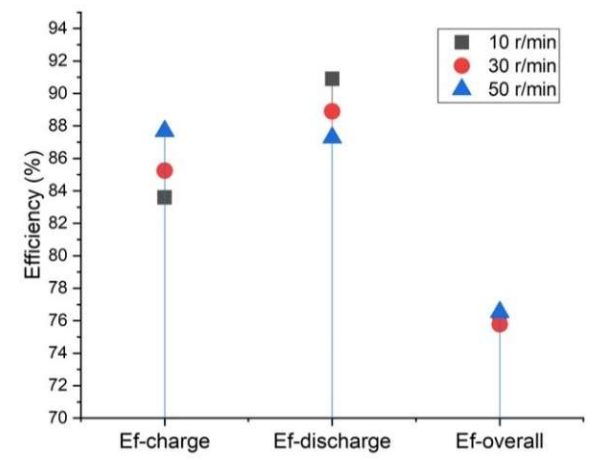

Figure 12. Charging/discharging efficiencies under different stirring speeds.

\subsection{Active Energy Consumption}

Although stirring can increase the heat transfer rate, there is active power consumption of the motor. Energy consumption is an important index for evaluating the economic efficiency of the heat exchanger. During the experimental, the speed of the stirring motor was controllable and constant and the power varied according to the load torque. The real-time power P-engine of the motor had been measured to analyze the stirring energy consumption under the following experimental conditions: rotating speed was $30 \mathrm{r} / \mathrm{min}$, inlet temperature of $\mathrm{HTF}$ was $90^{\circ} \mathrm{C}$ in charging process, inlet temperature of $\mathrm{HTF}$ was $20^{\circ} \mathrm{C}$ in discharging process, and mass flow rate was $50 \mathrm{~L} / \mathrm{h}$.

As presented in Figure 13a, at the beginning of the charging process, the motor operated at $305.8 \mathrm{~W}$ with overload but cannot overcome the frictional resistance between the solid paraffin and the heat transfer surface. After $15 \mathrm{~s}$, as the paraffin wax on the surface of the inner column wall became soft, the resistance of the stirring shaft quickly decreased, and the stirrer started to stir. After that, the motor power dropped to $20 \mathrm{~W}$ within $120 \mathrm{~s}$. And then, the motor power fluctuated between $15-17 \mathrm{~W}$ until the end of charging process. The average power of the motor was $16.08 \mathrm{~W}$, and the average charging rate was greater than $500 \mathrm{~J} / \mathrm{s}$. Therefor the energy consumed only accounts for less than $3.2 \%$ of the energy stored in PCM.

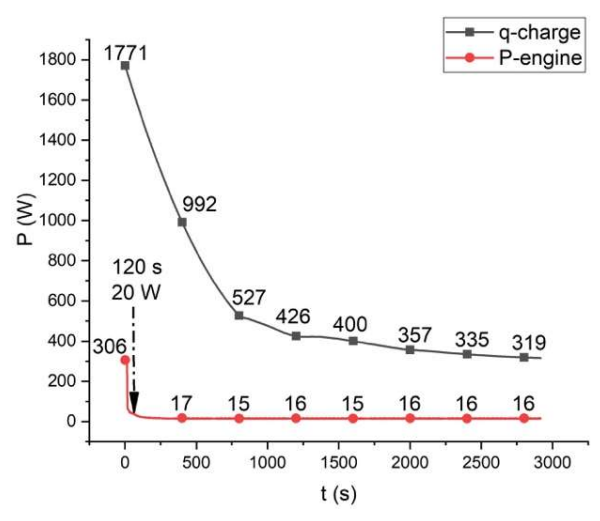

(a)

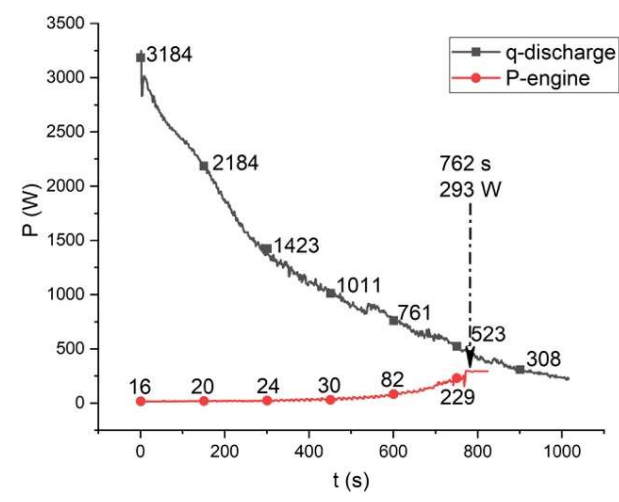

(b)

Figure 13. (a) Motor power and heat transfer rate during charging process, (b) motor power and heat transfer rate during discharging process.

As shown in Figure 13b, the minimum power of the motor was $16 \mathrm{~W}$. This is because the paraffin was initially liquid and the friction from the heat transfer surface was small. With the progress of the discharging, the paraffin gradually frozen into solid state, and the friction between the paraffin and the heat transfer surface gradually increased. At $762 \mathrm{~s}$, the motor power was $293 \mathrm{~W}$ and no longer stirring. Before the $600 \mathrm{~s}$, the average power of the motor was $30.3 \mathrm{~W}$, but average power was $56.9 \mathrm{~W}$ for the total discharging time. The average discharging rate was greater than $1100 \mathrm{~J} / \mathrm{s}$. Therefor the energy consumed accounts for less than $5.2 \%$ of the energy released by PCM. 
In order to reduce energy consumption, the stirring time during the charging/discharging processes should be controlled. During the charging process, the stirring only to be started when the paraffin in contact with the heat transfer surface turns to soft after a period of heating. During the discharging process, the stirring should be stopped before the motor reached the maximum power. Otherwise, when the motor cannot overcome the stirring resistance, it will only convert the electrical energy into the internal thermal energy, which will cause damage to the motor and waste energy.

\section{Conclusions}

The results of the present work will contribute to research that using stirring to enhance heat transfer performance of PCM. The experiment first verified the principle, and then analyzed the effects of the mass flow of the HTF, the inlet temperature of HTF and the stirring speed on the heat transfer performance, and finally discussed the relationship between the energy consumed by the motor with the heat transfer rate. The conclusions are summarized as follows:

(1) The average charging rate with stirring increased $32.23 \mathrm{~J} / \mathrm{s}$ than without stirring. The average discharging rate increased $47.39 \mathrm{~J} / \mathrm{s}$ than without stirring. The charging/discharging completion time with stirring had been shortened by $9.61 \%$ and $48.61 \%$ compared to without stirring, respectively. Phase change heat transfer performance can be improved by enhancing convective, and it is superior to the heat transfer mechanism based on conduction.

(2) With a mass flow rate from $50 \mathrm{~L} / \mathrm{h}$ to $100 \mathrm{~L} / \mathrm{h}$, the charging/discharging time was reduced by $38.78 \%$ and $37.99 \%$, the charging rate increased from $501.3 \mathrm{~J} / \mathrm{s}$ to $954.9 \mathrm{~J} / \mathrm{s}$, and the discharging rate increased from $1202.7 \mathrm{~J} / \mathrm{s}$ to $1974.2 \mathrm{~J} / \mathrm{s}$. The thermal efficiency during the charging process decreased as the mass flow increased. In order to improve the overall thermal efficiency of the system, the mass flow rate should be reduced, but at the same time the heat transfer time will be increased. For this reason, specific consideration should be made according to actual needs.

(3) With the HTF inlet temperature increasing, the heat transfer rate increased rapidly. From $80{ }^{\circ} \mathrm{C}$ to $100{ }^{\circ} \mathrm{C}$, the average charging/discharging rates increased by $81.17 \%$ and $6.44 \%$, respectively. The larger temperature difference between HTF and PCM, the higher heat transfer rate will be. In order to improve the overall thermal efficiency, it is necessary to reduce the heat loss and increase the charging/discharging heat amount.

(4) From $10 \mathrm{r} / \mathrm{min}$ to $50 \mathrm{r} / \mathrm{min}$, the charging rate increased from $480.6 \mathrm{~J} / \mathrm{s}$ to $545.9 \mathrm{~J} / \mathrm{s}$. The discharging rate increased from $1046.9 \mathrm{~J} / \mathrm{s}$ to $1397.5 \mathrm{~J} / \mathrm{s}$. Average heat transfer rates during charging/discharging processes increased with stirring speed but stirring has a more significant effect on discharging process. In order to improve the efficiency, stirring speed should increase during charging process and decrease during discharging process, but the effect on the heat transfer rate must also be considered.

(5) Under the charging process, average power of the motor was $16.08 \mathrm{~W}$, and the average charging rate was greater than $500 \mathrm{~J} / \mathrm{s}$, accounting for less than $3.2 \%$. Under the discharging process, the average power of the motor was $56.9 \mathrm{~W}$, the average discharging rate was greater than $1100 \mathrm{~J} / \mathrm{s}$, accounting for less than $5.2 \%$. In order to reduce energy consumption, the stirring time during the charging/discharging processes should be controlled.

Based on the above studies, it can be considered that the heat transfer mechanism dominated by forced convection can effectively improve the thermal performance of latent heat storage with lower power consumption. The next research will focus on optimizing heat transfer performance and reducing active energy consumption.

Author Contributions: All authors have read and agreed to the published version of the manuscript. Conceptualization, S.L. and Y.Z.; methodology, L.Y., Y.Z. and Y.S.; validation, S.L., X.Y., L.Y. and Y.S.; formal analysis, X.Y., L.S., X.H. and Y.Z.; investigation, Y.Z., X.Y. and L.S.; data curation, Y.Z., X.H. and L.S.; writing-original draft preparation, Y.Z; writing—review and editing, S.L.; supervision, S.L.; project administration, S.L.; funding acquisition, S.L.

Funding: This research was funded by The Thousand Young Talents Program of China and Graduate Technological Innovation Project of Beijing Institute of Technology. 
Conflicts of Interest: The authors declare no conflict of interest.

\section{Nomenclature}

$\begin{array}{ll}C p & \text { specific heat }(\mathrm{kJ} / \mathrm{kg} \mathrm{K}) \\ h & \text { enthalpy }(\mathrm{kJ} / \mathrm{kg}) \\ m & \text { mass }(\mathrm{kg}) \\ P & \text { power }(\mathrm{W}) \\ Q & \text { quantity of heat }(\mathrm{kJ}) \\ q & \text { heat transfer rate }(\mathrm{J} / \mathrm{s}) \\ T & \text { temperature }\left({ }^{\circ} \mathrm{C}\right) \\ t & \text { time }(\mathrm{s}) \\ u & \text { relative error }(\%) \\ \text { Greek symbol } & \\ \Delta & \text { difference value } \\ \eta & \text { efficiency }(\%) \\ \tau & \text { total time }(\mathrm{s}) \\ \text { Subscripts } & \\ \text { charge } & \text { charging process } \\ \text { discharge } & \text { discharging process } \\ \mathrm{f} & \text { heat transfer fluid } \\ \text { fin } & \text { final temperature } \\ \text { ini } & \text { initial temperature } \\ 1 & \text { liquid PCM } \\ \mathrm{m} & \text { melting } \\ \text { out } & \text { Outlet of shell container } \\ \text { pc } & \text { phase change material } \\ \text { s } & \text { solid PCM } \\ \text { shell } & \text { 304 stainless-steel shell } \\ \text { stored } & \text { stored capacity } \\ \text { tank } & \text { 304 stainless-steel tank }\end{array}$

\section{References}

1. BP Statistical Review of World Energy 2019. Available online: https://www.bp.com/content/dam/bp/businesssites/en/global/corporate/pdfs/energy-economics/statistical-review/bp-stats-review-2019-full-report.pdf (accessed on 13 June 2019).

2. Millar, R.J.; Fuglestvedt, J.S.; Friedlingstein, P.; Rogelj, J.; Grubb, M.J.; Matthews, H.D.; Skeie, R.B.; Forster, P.M.; Frame, D.J.; Allen, M.R. Emission budgets and pathways consistent with limiting warming to $1.5^{\circ} \mathrm{C}$. Nat. Geosci. 2017, 10, 741-747. [CrossRef]

3. Heffron, R.J.; Rønne, A.; Tomain, J.P.; Bradbrook, A.; Talus, K. A treatise for energy law. J. World Energy Law Bus. 2018, 11, 34-48. [CrossRef]

4. Huisingh, D.; Zhang, Z.; Moore, J.C.; Qiao, Q.; Li, Q. Recent advances in carbon emissions reduction: Policies, technologies, monitoring, assessment and modeling. J. Clean. Prod. 2015, 103, 1-12. [CrossRef]

5. Alva, G.; Lin, Y.; Fang, G. An overview of thermal energy storage systems. Energy 2018, 144, 341-378. [CrossRef]

6. Sarbu, I.; Dorca, A. Review on heat transfer analysis in thermal energy storage using latent heat storage systems and phase change materials. Int. J. Energy Res. 2018, 43, 29-64. [CrossRef]

7. Nazir, H.; Batool, M.; Osorio, F.J.B.; Isaza-Ruiz, M.; Xu, X.; Vignarooban, K.; Phelan, P.; Inamuddin; Kannan, A.M. Recent developments in phase change materials for energy storage applications: A review. Int. J. Heat Mass Tran. 2019, 129, 491-523. [CrossRef]

8. Peiro, G.; Gasia, J.; Miro, L.; Cabeza, L.F. Experimental evaluation at pilot plant scale of multiple PCMs (cascaded) vs. single PCM configuration for thermal energy storage. Renew. Energy 2015, 83, 729-736. [CrossRef]

9. Lin, Y.; Jia, Y.; Alva, G.; Fang, G. Review on thermal conductivity enhancement, thermal properties and applications of phase change materials in thermal energy storage. Renew. Sustain. Energy Rev. 2018, 82, 2730-2742. [CrossRef] 
10. Sheikholeslami, M. Numerical modeling of nano enhanced PCM solidification in an enclosure with metallic fin. J. Mol. Liq. 2018, 259, 424-438. [CrossRef]

11. Sharma, A.; Tyagi, V.V.; Chen, C.R.; Buddhi, D. Review on thermal energy storage with phase change materials and applications. Renew. Sustain. Energy Rev. 2009, 13, 318-345. [CrossRef]

12. Li, M.; Jin, B.; Ma, Z.; Yuan, F. Experimental and numerical study on the performance of a new high-temperature packed-bed thermal energy storage system with macroencapsulation of molten salt phase change material. Appl. Energy 2018, 221, 1-15. [CrossRef]

13. Shchukina, E.M.; Graham, M.; Zheng, Z.; Shchukin, D.G. Nanoencapsulation of phase change materials for advanced thermal energy storage systems. Chem. Soc. Rev. 2018, 47, 4156-4175. [CrossRef]

14. Sheikholeslami, M.; Ghasemi, A. Solidification heat transfer of nanofluid in existence of thermal radiation by means of FEM. Int. J. Heat Mass Tran. 2018, 123, 418-431. [CrossRef]

15. Sheikholeslami, M. Finite element method for PCM solidification in existence of CuO nanoparticles. J. Mol. Liq. 2018, 265, 347-355. [CrossRef]

16. Zhang, L.; Zhou, K.; Wei, Q.; Ma, L.; Ye, W.; Li, H.; Zhou, B.; Yu, Z.; Lin, C.; Luo, J.; et al. Thermal conductivity enhancement of phase change materials with $3 \mathrm{D}$ porous diamond foam for thermal energy storage. Appl. Energy 2019, 233-234, 208-219. [CrossRef]

17. Zheng, H.; Wang, C.; Liu, Q.; Tian, Z.; Fan, X. Thermal performance of copper foam/paraffin composite phase change material. Energy Convers. Manag. 2018, 157, 372-381. [CrossRef]

18. Stritih, U. An experimental study of enhanced heat transfer in rectangular PCM thermal storage. Int. J. Heat Mass Tran. 2004, 47, 2841-2847. [CrossRef]

19. Zipf, V.; Neuhäuser, A.; Willert, D.; Nitz, P.; Gschwander, S.; Platzer, W. High temperature latent heat storage with a screw heat exchanger: Design of prototype. Appl. Energy 2013, 109, 462-469. [CrossRef]

20. Assis, E.; Katsman, L.; Ziskind, G.; Letan, R. Numerical and experimental study of melting in a spherical shell. Int. J. Heat Mass Tran. 2007, 50, 1790-1804. [CrossRef]

21. Wang, Y.; Wang, L.; Xie, N.; Lin, X.; Chen, H. Experimental study on the melting and solidification behavior of erythritol in a vertical shell-and-tube latent heat thermal storage unit. Int. J. Heat Mass Tran. 2016, 99, 770-781. [CrossRef]

22. Xia, L.; Zhang, P.; Wang, R.Z.I.O.; Shanghai, J.T.U.; Shanghai, P.R.C. Numerical study of paraffin melting in a rectangular latent thermal energy storage unit. In Proceedings of the 2008 International Cryogenics and Refrigeration Conference, Shanghai, China, 5-9 April 2008; p. 5.

23. Safari, A.; Saidur, R.; Sulaiman, F.A.; Xu, Y.; Dong, J. A review on supercooling of Phase Change Materials in thermal energy storage systems. Renew. Sustain. Energy Rev. 2017, 70, 905-919. [CrossRef]

24. Dou, B.; Zhang, H.; Cui, G.; Wang, Z.; Jiang, B.; Wang, K.; Chen, H.; Xu, Y. Hydrogen production by sorption-enhanced chemical looping steam reforming of ethanol in an alternating fixed-bed reactor: Sorbent to catalyst ratio dependencies. Energy Convers. Manag. 2018, 155, 243-252. [CrossRef]

25. Hernandez-Parra, O.D.; Plana-Fattori, A.; Alvarez, G.; Ndoye, F.; Benkhelifa, H.; Flick, D. Modeling flow and heat transfer in a scraped surface heat exchanger during the production of sorbet. J. Food Eng. 2018, 221, 54-69. [CrossRef]

26. Maloney, J.O. Perry's Chemical Engineer's Handbook; The McGraw-Hill Companies, Inc.: New York, NY, USA, 1984.

27. Kumaresan, T.; Joshi, J.B. Effect of impeller design on the flow pattern and mixing in stirred tanks. Chem. Eng. J. 2006, 115, 173-193. [CrossRef]

28. Tsai, S.W. Heat-transfer in an inner loop reactor. Warme Stoffubertrag. Fluid Dyn. 1991, 26, 129-135. [CrossRef]

(C) 2020 by the authors. Licensee MDPI, Basel, Switzerland. This article is an open access article distributed under the terms and conditions of the Creative Commons Attribution (CC BY) license (http://creativecommons.org/licenses/by/4.0/). 